\section{Thrombin and Ethanolamine Injection Therapy in Arresting Uncontrolled Bleeding from Duodenal Varices}

Bleeding from duodenal varices is a life-threatening situation. A few cases of endoscopic injection therapy of duodenal varices have been reported $(1,2)$. We report here on the first case of combined thrombin and ethanolamine injection in the treatment of bleeding duodenal varices.

A 22-year-old male was admitted due to gastrointestinal bleeding. He had been previously diagnosed as having Caroli's disease, with hepatic fibrosis and portal vein cavernomatosis. Since 1983, he had presented with several episodes of hemorrhage due to esophageal and gastric varices, which were treated with drugs, injection therapy, and a proximal splenorenal shunt. During the present admission, gastroscopy showed a duodenal bulb varix with stigmata of recent bleeding. Somatostatin infusion was started, but rebleeding occurred 24 hours later. Laparotomy was performed in an attempt to place a mesocaval shunt, but was unsuccessful because of partial thrombosis of the superior mesenteric vein. Forty-eight hours after surgery, the patient presented massive hemorrhage, and active bleeding from the duodenal varix was seen. Injection therapy of the duodenal varix was performed intravariceally and perivariceally with $400 \mathrm{U}$ of bovine thrombin, followed by $10 \mathrm{ml}$ of $5 \%$ ethanolamine (Figure 1). Several hemostatic parameters were tested before and 30 minutes after thrombin injection, and no significant differences were observed Seven days later, a marked reduction in the size of the duodenal varix, with a small mucosal ulceration, was seen (Figure 2). The patient has remained free from bleeding for the following five months.

Several series have shown the effectiveness of thrombin in the treatment of hemorrhage from esophageal and gastric varices $(3,4)$. The first case of successful thrombin injection for bleeding duodenal varices was recently described (5). We have combined the immediate effectiveness of thrombin injection in arresting the bleeding with reduced doses of ethanolamine, to avoid the risk of mucosal ulceration or duodenal perforation. The optimal dose of thrombin remains unknown, and further studies are necessary before routine use of thrombin can be recommended. Our case indicates that associated thrombin and sclerosant injection therapy may be an effective and safe treatment for bleeding duodenal varices when other therapeutic procedures have failed.

\section{Sans', J. Llach', J. M. Bordas', V.Andreu', J. C. Reverter', J. Bosch ${ }^{3}$, F. Mondelo I, J. M. Salmerón ${ }^{3}$, A. Mas ${ }^{3}$.J. Terés! J. Rodés ${ }^{3}$ \\ Digestive Endoscopy and Gastroenterology Service \\ 'Hemostasis Service \\ ${ }^{3}$ Liver Unit, Hospital Clínic I Provincial, Barcelona, Spain}



Figure 1: Active hemorrhage from a duodenal varix before endoscopic thrombin injection commenced.

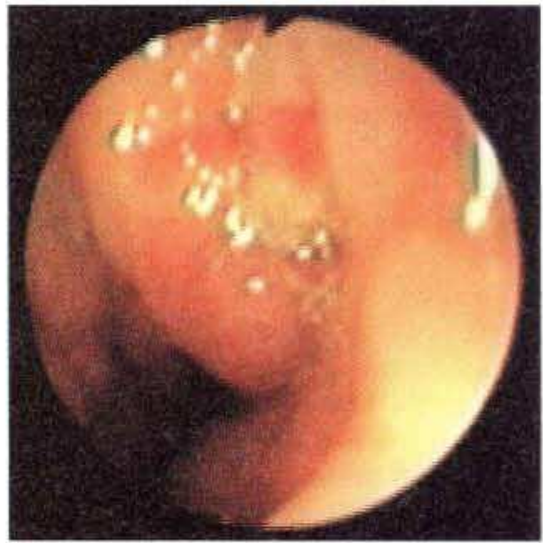

Figure 2: Endoscopic appearance of the duodenal bulb seven days after injection therapy A marked reduction in the size of the duodenal varix, and a small duodenal mucosal ulceration, were observed.

\section{References}

I. Sauerbruch T, Weinzierl M, Dietrich HP, et al. Sclerotherapy of a bleeding duodenal varix. Endoscopy 1982; 14: 187-9.

2. Kirkpatrick JR, Shoenut JP, Micflikier AB. Successful injection sclerotherapy for bleeding duodenal varix in intrahepatic portal obstruction. Gastrointest Endosc 1985; 31: 259-60.

3. Lyons SD, Sugawa C, Geller ER, et al. Comparison of 1\% sodium tetradecyl sulfate to a thrombogenic sclerosant cocktail for endoscopic sclerotherapy. Am Surg 1988; 54: 81-4.

4. Williams SGJ, Peters RA, Westaby D. Thrombin: an effective treatment for fundal gastric varices? Gut 1993; 34: S48.

5. Rai R, Panzer SW, Miskovsky E, et al. Thrombin injection for bleeding duodenal varices. Am J Gastroenterol 1994; 89: 18713 .

Corresponding Author

J. M. Bordas, M.D.

Section of Endoscopy

Hospital Clinic I Provincial

Villaroel 170

08036 Barcelona

Spain

Fax: $+34-3-2275454$ 